\title{
Comparative study of electrical test methods on detecting transformer faults
}

\author{
Sharin Ab Ghani' ${ }^{1}$, Mohd Shahril Ahmad Khiar ${ }^{1}$, Imran Sutan Chairul ${ }^{1}$, Nor Hidayah Rahim ${ }^{1}$, \\ Mohd Hisamuddin Kamaruzaini ${ }^{2}$ \\ ${ }^{1}$ High Voltage Engineering Research Laboratory, Faculty of Electrical Engineering, Universiti Teknikal Malaysia \\ Melaka, Hang Tuah Jaya, Melaka, Malaysia \\ ${ }^{2}$ Kaziman Resources, Selangor, Malaysia
}

\begin{tabular}{l}
\hline Article Info \\
\hline Article history: \\
Received Aug 2, 2021 \\
Revised Dec 8, 2021 \\
Accepted Dec 30, 2021 \\
\hline
\end{tabular}

Keywords:

Frequency response analysis

Insulation resistance

Short circuit

Transformer

Transformer turn-ratio

Winding deformation

\begin{abstract}
Condition monitoring of distribution and power transformers is of utmost importance to utilities due to cost effectiveness concerns. The common faults that occur in transformers are short circuits and winding deformation. To date, there are many established test methods used to detect these faults. In this study, three test methods (insulation resistance (IR), transformer turn ratio (TTR), and frequency response analysis (FRA)) were compared to assess their effectiveness in detecting short circuit and winding deformation in a three-phase transformer. Based on the results, the three test methods were found to be capable of detecting short circuits. However, only TTR and FRA can detect winding deformation, and FRA can further indicate which phase is faulty. Therefore, it is concluded that FRA is more effective in detecting short circuit and winding deformation of a three-phase transformer.
\end{abstract}

This is an open access article under the CC BY-SA license.

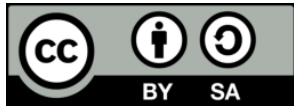

\section{Corresponding Author:}

Sharin Ab Ghani

High Voltage Engineering Research Laboratory, Faculty of Electrical Engineering

Universiti Teknikal Malaysia Melaka

Hang Tuah Jaya, 76100 Durian Tunggal, Melaka, Malaysia

E-mail: sharinag@utem.edu.my

\section{INTRODUCTION}

Transformer is one of the costliest equipment in an electrical power grid. Transformers play an important role to ensure reliable electricity supply. Transformers are subjected to thermal, mechanical, and electrical stresses throughout their lifetime. Studies have identified that transformer failures frequently occur in windings $(49.4 \%)$, tap changers $(23 \%)$, bushings $(13 \%)$, lead exits $(6.4 \%)$, cores $(3.7 \%)$, and others $(3.9 \%)$ [1], [2]. Failure of a transformer component will result in significant financial losses because the transformer will be out of service for extended periods, and this includes the cost of repair or replacement. Hence, it is crucial to detect transformer faults as early as possible to prevent catastrophic failure of the transformer [3], [4]. It is, therefore, necessary to detect any fault within the transformer at an early stage to prevent any unplanned failure [5], [6]. The majority of transformer faults is due to windings, which is a major concern to manufacturers. On average, the life expectancy of oil-immersed and dry-type transformers is more than 30 years [7], [8]. Despite the seemingly long-life expectancy, the life expectancy of transformers is dependent on the condition of the insulation system. The insulation system will degrade over time, which will shorten the life expectancy of transformers. The majority of transformer faults occur in windings such as short circuits and winding deformation [9]. Short circuits tend to occur when the transformer becomes hot as plenty of dust adhere to the transformer over the years. Winding deformation refers to a displacement of the coil windings, where the windings may also bulge. Winding deformation is mainly caused by the axial 
leakage flux between the inner and outer coils. The coil is stretched by a radial force, which compresses the inner coil. This induces pressure on the line ring, resulting in partial coil wire bending. The bending moment will further increase, resulting in an "avalanche". Insulation resistance (IR), transformer turn ratio (TTR), and frequency response analysis (FRA) are frequently used to assess the health of transformers [10]. Short circuits can occur across any two lines or when the neutral point of the transformer is grounded between any lines [11]. Figure 1(a) shows an impact of continuous overcurrent causing transformer to become short circuit. Meanwhile, Figure 1(b) shows another impact of overcurrent by developing winding deformation. To date, utilities implement a strategy to monitor the condition of transformers through three tiers namely, i) tier 1-routine online condition assessment, ii) tier 2-offline condition assessment, and iii) tier 3-advanced condition assessment [12]-[15]. Tier 1 pertains to chemical tests such as dissolved gas analysis, oil analysis, and thermography. Electrical test methods such as IR and TTR are also used to monitor the condition of transformer and are categorized under tier 2, while FRA is categorized under tier 3. All of these methods can be used to detect transformer faults based on their technology, system advancement, robustness, and pricing. In this study, the effectiveness of IR, TTR, and FRA in detecting common transformer faults (short circuit and winding deformation) is assessed. It is believed that the findings of this study will facilitate industrial practitioners to identify which electrical test method is best for condition monitoring of transformers.

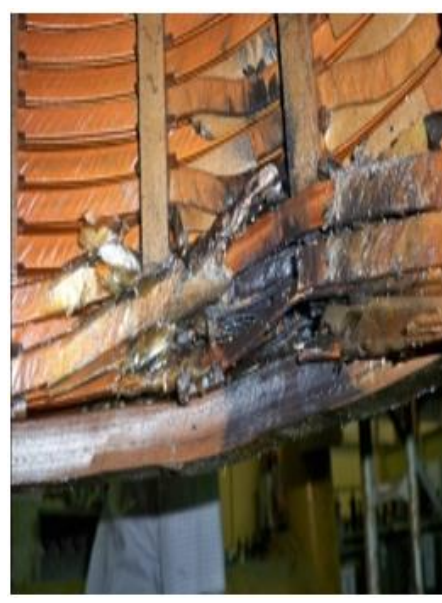

(a)

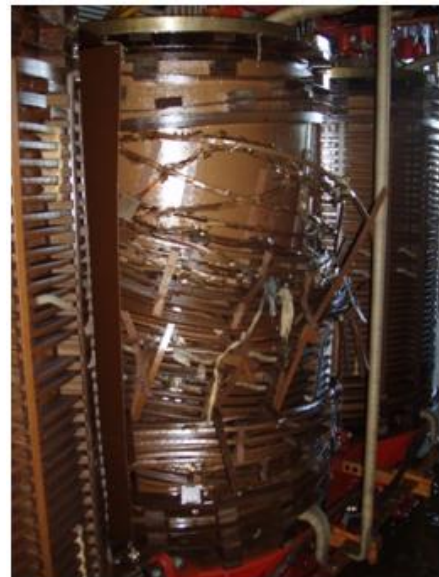

(b)

Figure 1. Transformer faults: (a) short circuit and (b) winding deformation [11]

- Insulation resistance

IR test is focused on measuring the current that flows through an insulation or isolating structure upon the application of a DC voltage [16]. The IR of a transformer is measured between high voltage winding and low voltage/earth winding with respect to ground [17]. The measurement readings are taken from three locations: i) high voltage side, ii) low voltage side, and iii) high-to-low voltage side. The polarization index (PI) is used to assess the IR, and is given by (1),

$$
\mathrm{PI}=\frac{I R_{10}}{I R_{1}}
$$

where $I R_{10}$ and $I R_{1}$ denote the IR reading at $10 \mathrm{~min}$ and $1 \mathrm{~min}$, respectively.

- Transformer turn ratio

In the TTR test, the turn ratio, phase shift, and excitation current of distribution and power transformers are measured [16], [18]. The IEEE C57.12.90-2015 standard is the standard test code for oil-immersed distribution and power transformers [19]. The turn ratio is basically a voltage ratio to evaluate the condition of the transformer windings, and can be determined using (2), (3) and (4).

Rated transformer voltage ratio $=\frac{\text { Primary voltage }}{\text { Secondary voltage } / \sqrt{3}}$

Measured transformer voltage ratio $=\frac{\text { Primary voltage }}{\text { Secondary voltage }}$ 


$$
\operatorname{TTR}(\%)=\frac{\text { Rated ratio }- \text { Measured ratio }}{\text { Rated } \text { ratio }} \times 100
$$

\section{- Frequency response analysis}

FRA involves calculating the impedance of a transformer winding across a wide range of frequencies and the results are compared with a reference set [20], [21]. This test method is being gradually introduced in the field of power transformer testing and diagnosis [22]. FRA or sweep frequency response analysis can determine if the transformer windings have displaced from their original positions. The FRA results can be used to assess tramsformer faults and the transformer can be further examined using other methods. The condition of the transformer (good, fair, poor, bad) can be identified based on the tolerance conditions according to the IEEE standard [23], [24]. For the FRA measurements, the preset signal ( $\left.\mathrm{V}_{\text {in }}\right)$ was injected on the line lead, and the response $\left(\mathrm{V}_{\text {out }}\right)$ was detected on the neutral lead of the transformer. Based on the transfer function (TF), the frequency response magnitude is the attenuated voltage in decibels (dB), as given by (5). The FRA is typically described by two-dimensional Bode diagrams, where the $\mathrm{x}$ - and $\mathrm{y}$-axes denote the frequency and frequency response magnitude, respectively.

$$
\mathrm{TF}(\text { in } \mathrm{dB})=20 \log \left(\frac{V_{\text {out }}}{V_{\text {in }}}\right)
$$

\section{METHODOLOGY}

In this study, a three-phase transformer with a step-down rating of 255/60 VAC was used (Table 1 and Figure 2(a)). The turn-to-turn varnish insulation was removed in order to simulate a short circuit on the transformer winding, as shown in Figure 2(b). Sandpapers with a grit size of 500 and 1000 were used for this purpose. The winding deformation was simulated by applying force to shift the secondary winding of the transformer from its original position, as shown in Figure 2(c). It shall be noted that the faults were applied only at the red phase low voltage winding while the other phases remained normal.

\begin{tabular}{ll}
\multicolumn{1}{c}{ Table 1. Details of the tested transformer } \\
\hline \multicolumn{1}{c}{ Parameter } & \multicolumn{1}{c}{ Detail } \\
\hline Model & DE LORENZO \\
Capacity & Three-phase \\
High voltage winding & 255 V Delta connected \\
Low voltage winding & 60 V Star connected \\
Rating & 350 VA \\
\hline
\end{tabular}

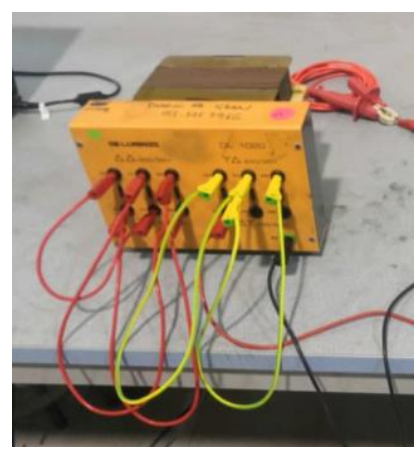

(a)

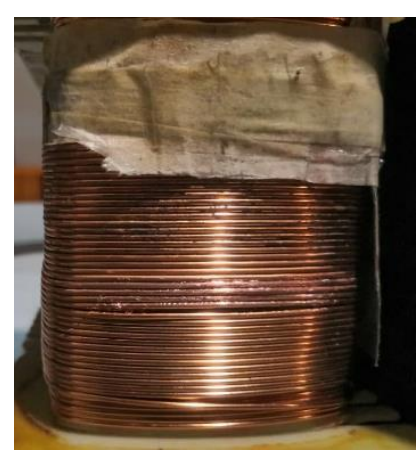

(b)

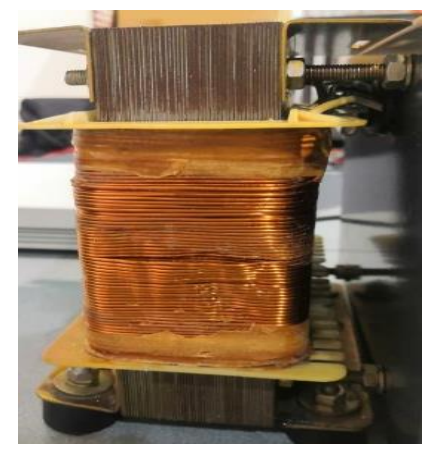

(c)

Figure 2. Photographs of the tested transformer: (a) connections of the transformer, (b) short circuit, and (c) winding deformation.

\section{RESULTS AND DISCUSSION}

The results obtained in this study are categorized into three transformer conditions: i) normal condition, ii) short circuit condition, and iii) winding deformation condition. Testing results of insulation resistance (IR), transformer turn ratio (TTR) and frequency response analysis (FRA) from each category are presented in this section. Then, discussion is made to determine which testing method that capable to determine overall types of electrical faults (short circuit and winding deformation). 


\subsection{Transformer in normal condition}

Figure 3(a) shows the results of the IR measurements based on the PI mode. The PI is the ratio of the IR at $10 \mathrm{~min}$ divided by the IR at $1 \mathrm{~min}$, where a voltage of $250 \mathrm{VDC}$ was injected at the low voltage side. The PI values for the red phase show an opposing trend to the PI values for the blue phase. In contrast, the PI values are rather invariant, unlike the fluctuating patterns observed for the red and blue phases. Figure 3(b) shows the TTR test results for normal transformer condition. It can be seen that the PI values for the red phase are similar to those for the blue phase. By contrast, the PI values for the yellow phase show an increasing trend and differ significantly from those for the red and blue phases. It shall be noted that the age of the transformer is more than 10 years. Therefore, it can be expected that the readings of each phase will differ from one another, though the transformer is still in good condition. Figure 4 shows the FRA results for all three phases of the low voltage winding. It can be observed that all of the measured traces are identical to one another throughout the frequency range, indicating that the transformer is in good condition.

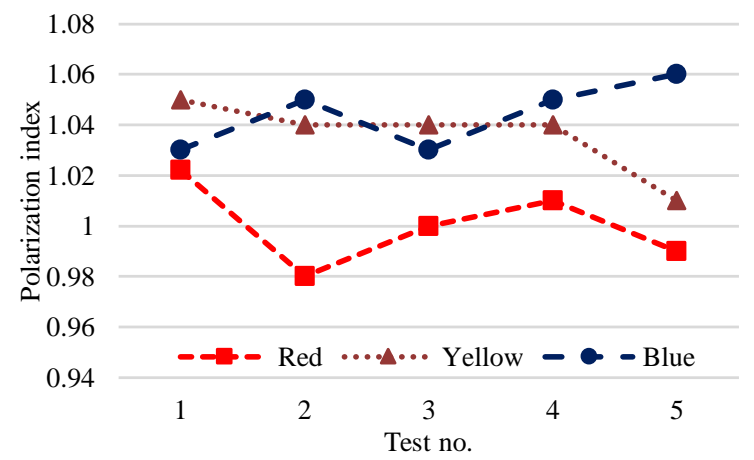

(a)

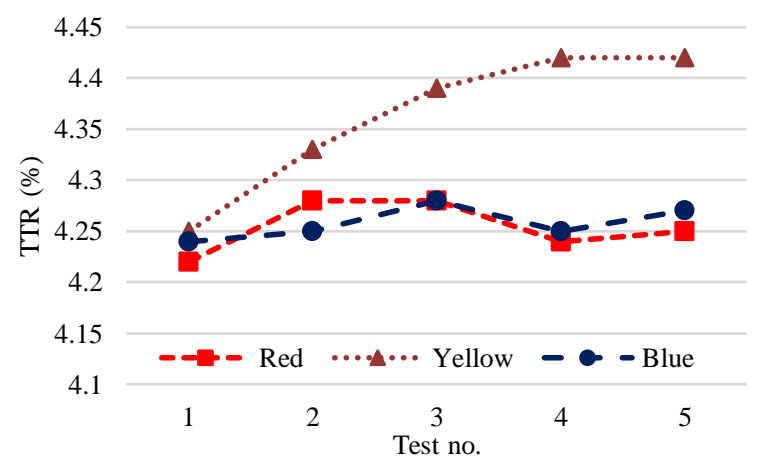

(b)

Figure 3. Test results for normal transformer condition: (a) IR measurements (PI mode) and (b) TTR measurements

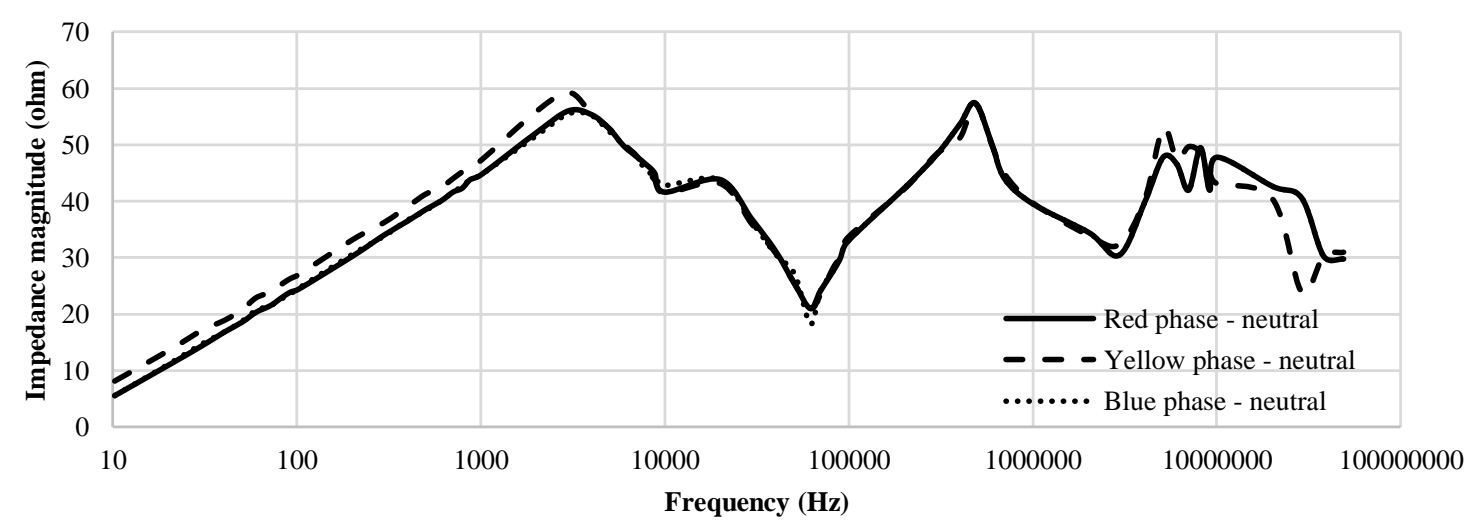

Figure 4. Results of the FRA measurements for normal transformer condition

\subsection{Transformer in short circuit condition}

Figure 5(a) shows the results of the IR measurements in PI mode for the transformer in short circuit condition. It is apparent that the PI values are higher for the red phase compared with those for other phases, except for the fifth test, where the PI values for the red and yellow phase coincide. The results can be attributed to the short circuit in the red phase low voltage winding. During the TTR test, a short circuit occurs in the red phase, as shown in Figure 5(b). When compared to the typical state, the turn ratio reveals a distinct pattern. According to Ohm's law, when the current in a short circuit is high, the voltage will be low. Since the short circuit occurs in the red phase, the percentage of error of the red phase is lower compared with those for the other phases. Figure 6 shows how the short circuit at the red phase primary winding affects the transformer winding. The number of turns is reduced when a short circuit occurs within the winding. The 
flux produced in the coil decreases as the number of turns in the coil decreases. When compared to the normal transformer condition, the initial response anti-resonance shifts slightly to the right, as indicated by the black boxes. The results are indeed expected because the short circuit occurs in the red phase winding and the frequency response for the red phase winding shifts significantly from those for the yellow and blue phases.

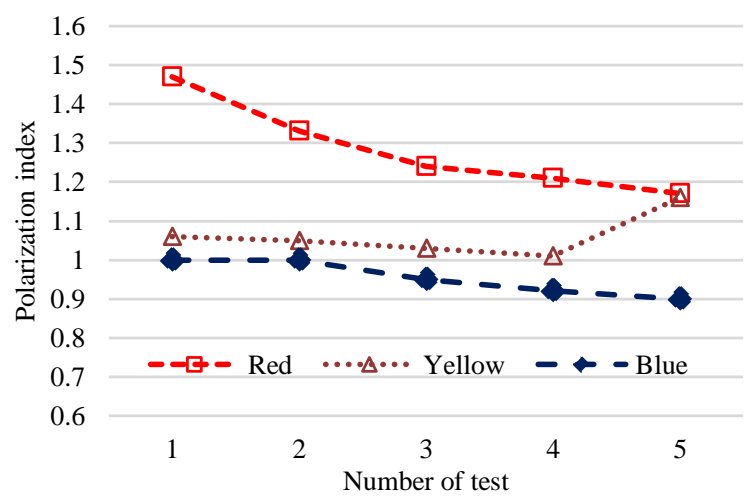

(a)

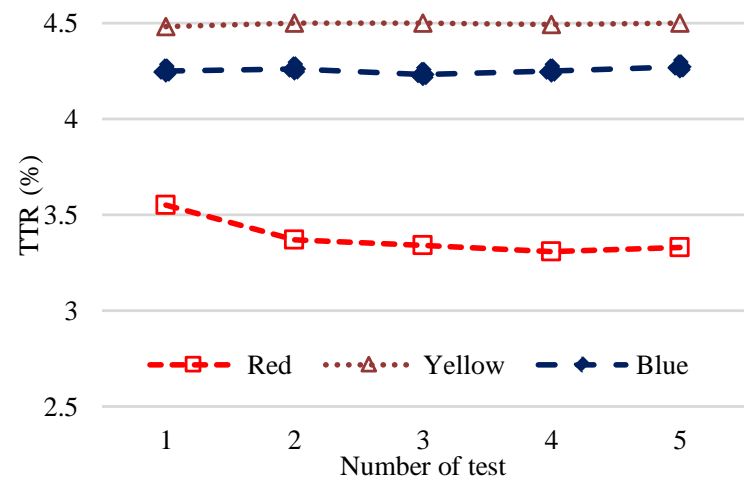

(b)

Figure 5. Test results for the transformer with short circuit: (a) IR measurements (PI mode) and (b) TTR measurements

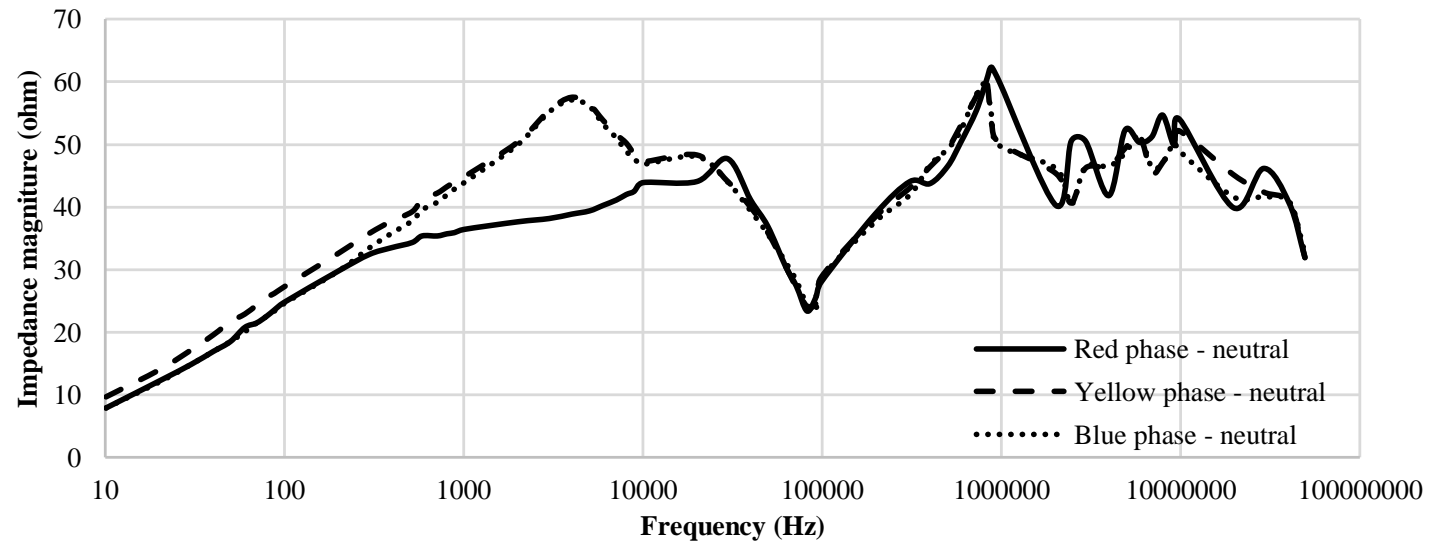

Figure 6. Results of the FRA measurements for the transformer with short circuit

\subsection{Transformer in winding deformation condition}

Based on the results shown in Figure 7(a), the PI values of faulty phase (red phase) are lower than those of the normal phases (yellow and blue phases). The PI values show a similar trend to one another and thus, it is difficult to distinguish whether winding deformation has occurred based on the IR results alone. Based on the results shown in Figure 7(b), it is possible to distinguish that winding deformation has occurred, though it is not possible to identify which phase is faulty. Since the fault occurs in the red phase, this fault also affects the yellow phase due to the flux distribution centered between the red and yellow phases. By contrast, based on the FRA measurements, there is a significant shift in the red phase due to winding deformation, as indicated by the black boxes shown in Figure 8. According to Yousof et al. [25], the frequency range for winding interaction is between 2 and $20 \mathrm{kHz}$, while the frequency range for the winding structure is between $20 \mathrm{kHz}$ and $1 \mathrm{MHz}$. Hence, FRA can be used as a means to indicate which phase is faulty, particularly winding deformation, unlike the IR and TTR methods. 


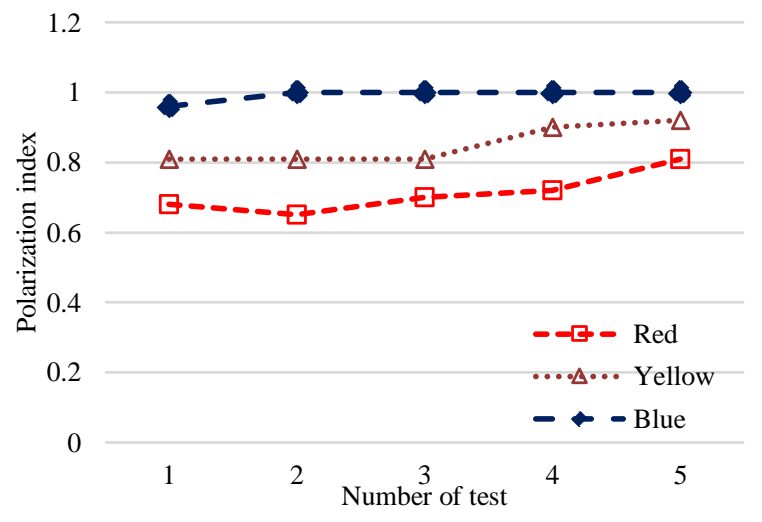

(a)

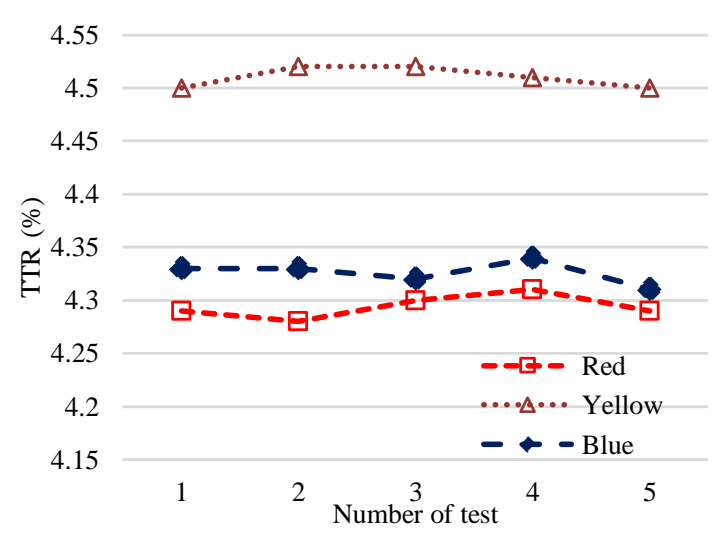

(b)

Figure 7. Test results for the transformer with winding deformation: (a) IR measurements (PI mode) and (b) TTR measurements

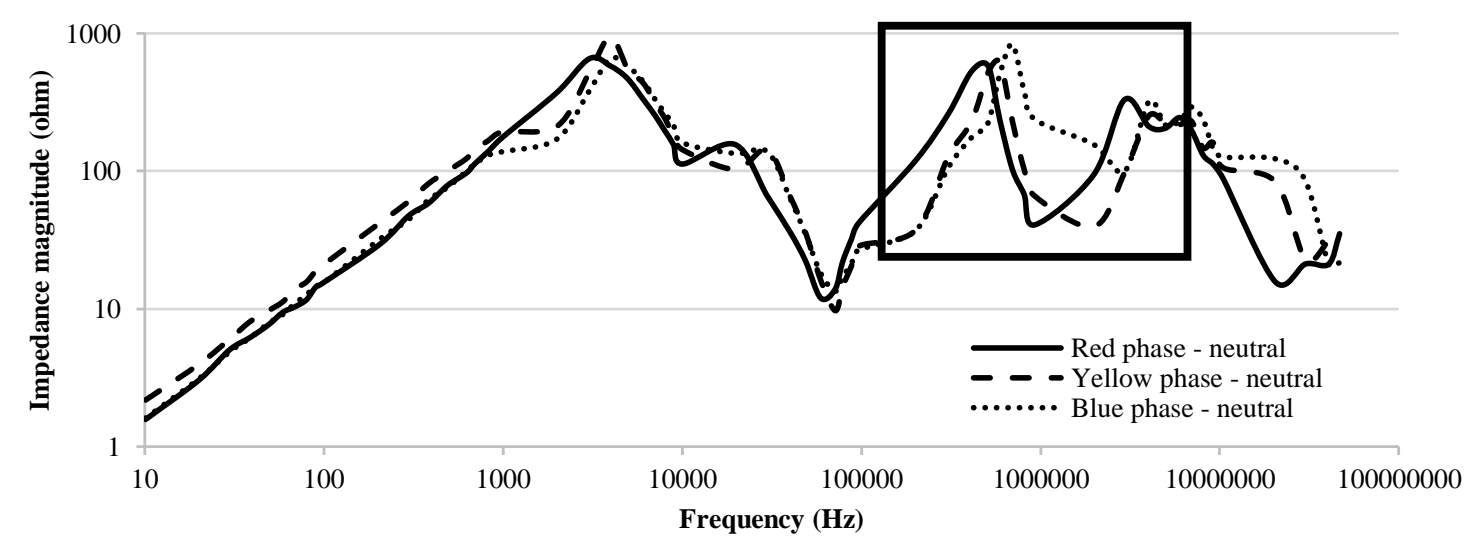

Figure 8. Results of the FRA measurements for the transformer with winding deformation

\section{CONCLUSION}

In this study, three test methods (IR, TTR, and FRA) used to detect short circuit and winding deformation faults in a transformer were compared. Based on the results, the IR, TTR, and FRA methods are capable of detecting short circuits in the transformer. The TTR and FRA methods can detect winding deformation, though the former can only detect that winding deformation occurs whereas the latter can both detect and indicate which phase undergoes winding deformation. FRA can be used to identify both short circuit and winding deformation faults based on the differences between the impedance of the normal phase (i.e., fingerprint) and faulty phase. Hence, FRA is more effective compared with IR and TTR in detecting short circuit and winding deformation in a transformer.

\section{ACKNOWLEDGEMENTS}

The authors gratefully acknowledge the financial support provided by the Universiti Teknikal Malaysia Melaka (UTeM). The authors specially thank Mr. Mohd Wahyudi Md Hussain from Faculty of Electrical Engineering, UTeM, for his assistance in preparing the test setup and carrying out the measurements in this study. The authors also wish to thank Ms. Nadia Abdullah from The Golden Touch Language-Editing Service for proofreading this paper.

\section{REFERENCES}

[1] N. F. M. Yasid, M. F. M. Yousof, R. A. Rahman, H. Zainuddin, and S. A. Ghani, "The effect of short circuit fault on one winding to other windings in FRA," International Journal of Power Electronics and Drive Systems, vol. 10, no. 2, pp. 585-593, 2019, doi: 10.11591/ijpeds.v10.i2.pp585-593. 
[2] CIGRE Working Group A2.37, Transformer Reliability Survey, e-cigre, pp. 1-122, 2015.

[3] S. Tenbohlen, S. Coenen, M. Djamali, A. Müller, M. H. Samimi, and M. Siegel, "Diagnostic Measurements for Power Transformers," Energies, vol. 9, no. 5, 2016, doi: 10.3390/en9050347.

[4] J. S. N'cho, I. Fofana, Y. Hadjadj, and A. Beroual, "Review of Physicochemical-Based Diagnostic Techniques for Assessing Insulation Condition in Aged Transformers," Energies, vol. 9, no. 5, 2016, doi: 10.3390/en9050367.

[5] C. Rajotte et al., Cigré Brochure 445 - Guide for Transformer Maintenance, CIGRE Technical Brochure, 2011.

[6] H. de Faria, J. G. S. Costa, and J. L. M. Olivas, "A review of monitoring methods for predictive maintenance of electric power transformers based on dissolved gas analysis," Renewable and Sustainable Energy Reviews, vol. 46, pp. 201-209, 2015, doi: 10.1016/j.rser.2015.02.052.

[7] Y. Z. Y. Ghazali, M. A. Talib, and A. M. Soosai, "TNB approach on managing asset retirement for distribution transformers," in 23rd International Conference on Electricity Distribution, 2015.

[8] M. M. Islam, G. Lee, and S. N. Hettiwatte, "A review of condition monitoring techniques and diagnostic tests for lifetime estimation of power transformers," Electrical Engineering, vol. 100, no. 2, pp. 581-605, 2018, doi: 10.1007/s00202-017-0532-4.

[9] S. Ab Ghani, Y. H. Md Thayoob, Y. Z. Y. Ghazali, M. S. A. Khiar, and I. S. Chairul, "Evaluation of transformer core and winding conditions from SFRA measurement results using statistical techniques for distribution transformers," 2012 IEEE International Power Engineering and Optimization Conference Melaka, Malaysia, 2012, pp. 448-453, doi: 10.1109/PEOCO.2012.6230906.

[10] M. K. Ilampoornan and M. Vikas, "Transformer fault detection by frequency response analysis," IOSR Journal of Electrical and Electronics Engineering, vol. 1, no. 4, pp. 27-32, 2012, doi: 10.9790/1676-0142732.

[11] S. A. Ghani, Y. H. M. Thayoob, Y. Z. Y. Ghazali, M. S. A. Khiar, and I. S. Chairul, "Condition Monitoring of Distribution Transformer's Mechanical Parts Using Sweep Frequency Response Analysis (SFRA),” Procedia Engineering, vol. 68, pp. 469476, 2013, doi: 10.1016/j.proeng.2013.12.208.

[12] Y. Z. Y. Ghazali, M. A. Talib, and H. A. Rosli, "TNB Experience in Condition Assessment and Life Management of Distribution Power Transformers," in 20th International Conference on Electricity Distribution, 2009, pp. 8-11.

[13] A. M. Selva et al., "Application of statistical distribution models to predict health index for condition-based management of transformers," Applied Sciences, vol. 11, no. 6, 2021, doi: 10.3390/app11062728.

[14] E. J. Kadim, N. Azis, J. Jasni, S. A. Ahmad, and M. A. Talib, "Transformers health index assessment based on neural-fuzzy network," Energies, vol. 11, no. 4, 2018, doi: 10.3390/en11040710.

[15] A. M. Selva et al., "Application of markov model to estimate individual condition parameters for transformers," Energies, vol. 11, no. 8, 2018, doi: 10.3390/en11082114.

[16] P. Gill, Electrical Power Equipment Maintenance and Testing, Florida, USA: CRC Press, 2016, doi: 10.1201/9781420017557.

[17] Y. Zhao, X. Li, J. Chen, and X. Tian, "Statistical Analysis of Insulation Resistance and Dielectric Loss of Transformer Based on Significance Difference," Gaoya Dianqi/High Voltage Apparatus, no. 9, pp. 123-128, 2018, doi: 10.13296/j.10011609.hva.2018.09.019.

[18] A. Prasetyo and E. Supriyanto, "Failure Analysis of Power Transformer Based on Transformer Turn Ratio Test and SFRA," in Journal of Physics: Conference Series, vol. 1817, no. 1, 2021, doi: 10.1088/1742-6596/1817/1/012021.

[19] “IEEE Standard Test Code for Liquid-Immersed Distribution, Power, and Regulating Transformers," in IEEE Std C57.12.90-2015 (Revision of IEEE Std C57.12.90-2010), vol., no., pp.1-120, 11 March 2016, doi: 10.1109/IEEESTD.2016.7428800.

[20] S. Al-Ameri, M. F. M. Yousof, N. Azis, S. Avinash, M. A. Talib, and A. A. Salem, "Frequency response of transformer winding to investigate the influence of RLC," Indonesian Journal of Electrical Engineering and Computer Science, vol. 14, no. 1, pp. 219229, 2019, doi: 10.11591/ijeecs.v14.i1.pp219-229.

[21] S. M. A. N. Al-Ameri et al., "Understanding the Influence of Power Transformer Faults on the Frequency Response Signature Using Simulation Analysis and Statistical Indicators," in IEEE Access, vol. 9, pp. 70935-70947, 2021, doi: 10.1109/ACCESS.2021.3076984.

[22] N. F. B. M. Yasid, A. A. M. Alawady, M. F. M. Yousof, M. A. Talib, and M. S. Kamarudin, "The effect of short circuit fault in three-phase core-typed transformer," International Journal of Power Electronics and Drive Systems, vol. 11, no. 1, pp. 409-416, 2020, doi: 10.11591/ijpeds.v11.i1.pp409-416.

[23] "IEEE Guide for the Application and Interpretation of Frequency Response Analysis for Oil-Immersed Transformers," in IEEE Std C57.149-2012, pp.1-72, 8 March 2013, doi: 10.1109/IEEESTD.2013.6475950.

[24] S. Ab Ghani, Y. H. Md Thayoob, Y. Z. Y. Ghazali, M. S. A. Khiar, I. S. Chairul, and M. S. Mohamad, "Comparative Study of Worldwide Standards for Interpreting Frequency Response Analysis (FRA) Results of Distribution Transformers," Applied Mechanics and Materials, vol. 793, pp. 144-148, 2015, doi: 10.4028/www.scientific.net/AMM.793.144.

[25] M. F. M. Yousof, C. Ekanayake, and T. K. Saha, "Frequency response analysis to investigate deformation of transformer winding," in IEEE Transactions on Dielectrics and Electrical Insulation, vol. 22, no. 4, pp. 2359-2367, August 2015, doi: 10.1109/TDEI.2015.004750.

\section{BIOGRAPHIES OF AUTHORS}

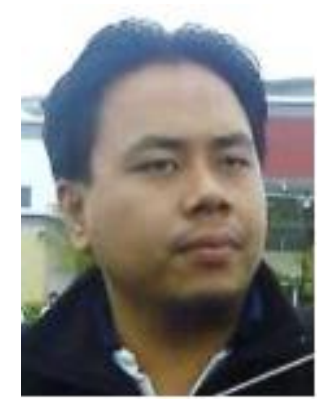

Sharin Ab Ghani (iD \& SC P received his BEng. (Hons.) degree in Electrical Engineering from Universiti Teknikal Malaysia Melaka (UTeM) in 2008, MEng. Degree in Electrical Engineering from Universiti Tenaga Nasional in 2012, and $\mathrm{PhD}$ degree in Electrical Engineering from Universiti Teknologi Malaysia in 2019. Currently, he is serving as Senior Lecturer at Faculty of Electrical Engineering, UTeM and Head of Energy and Power Systems (EPS) Research Group. His research interests are centered on high voltage engineering, condition monitoring of power equipment, eco-friendly electrical insulation, design of experiments, and optimization. He also has experience in consultation work with industries related to electrical installation design, transformer condition assessment, and partial discharge analysis. He can be contacted at email: sharinag@utem.edu.my. 

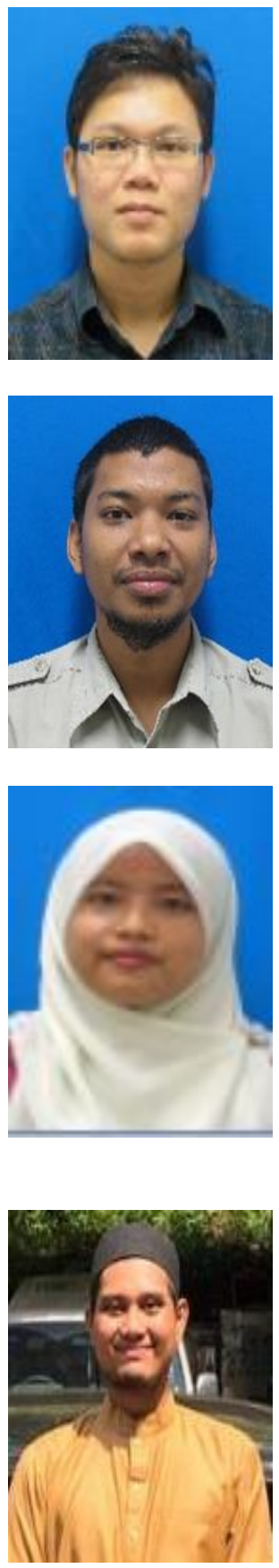

Mohd Shahril Ahmad Khiar (D) SI SC P received his BSc. in Electrical \& Electronics Engineering from Korea University in 2008, Master's degree in Electrical Engineering from Universiti Tenaga Nasional in 2012, and PhD degree from University of Southampton, UK in 2019. He is currently serving as Senior Lecturer at Faculty of Electrical Engineering, UTeM and Head of High Voltage Engineering Research Laboratory in UTeM, where he is also the Deputy Head of Energy and Power Systems (EPS) Research Group. His research interests include high voltage engineering and insulation materials, sensors, condition monitoring for power equipment, and asset management. Since 2013, he has published over 20 refereed conference and journal papers associated with the transformer condition monitoring and asset management. He can be contacted at email: mohd.shahril@utem.edu.my.

Imran Sutan Chairul (D) 8S SC P was born in Kuala Lumpur, Malaysia, in 1984. He received his BEng. (Hons.) degree in Electrical Engineering from Universiti Teknikal Malaysia Melaka (UTeM) in 2008 and MEng. degree in Electrical Engineering from Universiti Tenaga Nasional in 2012. He is currently pursuing his $\mathrm{PhD}$ degree at UTeM, where his research is focused on vegetable-based transformer dielectric liquids. $\mathrm{He}$ can be contacted at email: imransc@utem.edu.my.

Nor Hidayah Rahim (iD $8 \mathrm{SC}$ S received her BEng. in Electrical Engineering from Universiti Teknologi Malaysia in 2008 and her M.Eng. degree in Electrical Engineering from Universiti Tenaga Nasional, Malaysia in 2012. She recently completed her Ph.D. degree at Universiti Teknologi Malaysia. She is now a Senior Lecturer at Faculty of Electrical Engineering, Universiti Teknikal Malaysia Melaka. Her research interests include high voltage engineering and dielectric materials. She can be contacted at email: hidayah.rahim@utem.edu.my.

Mohd Hisamuddin Kamaruzaini (iD) 8 SC P received his diploma and bachelor's degree in electrical engineering from Universiti Teknikal Malaysia Melaka (UTeM) in 2016 and 2019, respectively. Currently, he is serving as Electrical Engineer at Kaziman Resources. He can be contacted at email: hisamuddin@gmail.com. 